\title{
Effects of reducing the starch content in oat-based diets with cellulose on jejunal flow and absorption of glucose over an isolated loop of jejunum in pigs
}

\author{
BY HELLE N. JOHANSEN ${ }^{1,2}$ AND K. E. BACH KNUDSEN ${ }^{1}$ \\ ${ }^{1}$ National Institute of Animal Science, Department of Animal Physiology and Biochemistry, \\ Research Centre Foulum, PO Box 39, DK-8830 Tjele, Denmark \\ ${ }^{2}$ Research Department of Human Nutrition, The Royal Veterinary and Agricultural University, \\ Rolighedsvej 25, DK-1870 Frederiksberg C, Copenhagen, Denmark
}

(Received 28 July 1993 - Revised 9 March 1994 - Accepted 23 March 1994)

\begin{abstract}
Four pigs fitted with two sets of re-entrant cannulas in the upper jejunum were used to study the effect of two oat-fiour (F)- and oat-bran (B)-based diets without or with (FC and BC respectively) addition of $148 \mathrm{~g}$ wood cellulose/ $\mathrm{kg}$ on jejunal flow and absorption of glucose over an isolated loop of jejunum. Mean transit time (MTT) of flow from the proximal re-entrant cannula increased from approximately $1.5 \mathrm{~h}$ with diet $\mathrm{F}$ to $\mathbf{2} \mathrm{h}$ when feeding diet BC. Both the replacement of oat flour by oat bran and the supplementation of the diets with cellulose led to a significantly longer MTT for dry matter and the carbohydrates, except that cellulose did not have a significant effect on the MTT for the total non-starch polysaccharides. Only the addition of cellulose significantly delayed gastric emptying of the added liquidphase (Polyethylene glycol 4000) and solid-phase $\left(\mathrm{Cr}_{2} \mathrm{O}_{3}\right)$ markers, whereas no effect of the oat source used was seen. Feeding diets with a higher level of dietary fibre (DF) and lower content of starch, obtained by substitution with cellulose or by feeding oat bran instead of oat flour, reduced the recovery of starch from an isolated loop of jejunum. Consequently, the quantitative absorption of starch was not significantly different between diets when starch was related to the recovery of external markers. However, when related to the recovery of arabinoxylan (AX) there was a significantly lower absorption of starch from the bran-based diets in comparison with the flour-based diets. The capacity to digest and absorb the large quantities of starch entering the duodenum after a carbohydrate-rich meal appears to be the limiting factor for absorption in the upper jejunum. Therefore, any effect of DF on the rate of absorption of glucose is presumably an effect on gastric emptying rather than displacement of the site of starch absorption in the small intestine.
\end{abstract}

Dietary fibre: Gastric emptying: Glucose

Most of the present knowledge about the physiological and nutritional effects of soluble dietary fibre (DF) is achieved under strictly controlled experimental conditions with simple physiological media (Johnson, 1990) leaving a large gap in studies of the nutritional implications under normal meal conditions, where the effects of DF often are confounded by changes in other dietary elements (Flourie, 1992). It is generally accepted that most soluble-DF sources reduce postprandial glycaemia, and the ability to raise intestinal viscosity is generally considered as being a determining factor.

Whether the diminished postprandial glycaemic response to carbohydrate meals after addition of soluble DF is caused by a slower gastric emptying (Holt et al. 1979; Torsdottir et al. 1991), delayed glucose absorption as a direct effect of the DF in the small intestine (Blackburn et al. 1984; Edwards et al. 1987), or both (Ebihara et al. 1981; Meyer et al. 1988; Cherbut et al. 1990), is still an unresolved issue. 
The effect of plant food sources naturally rich in soluble DF on gastric emptying and glucose absorption has not been studied as extensively as DF isolates. The action of soluble DF, when present in cell-wall structures, e.g. $\beta$-glucan in barley and oats, is likely to behave differently from fully hydrated viscous non-starch polysaccharides (NSP), since only a fraction is solubilized and, thereby, able to contribute to gut viscosity (Wood et al. 1990; Johansen, 1993). In a recent study with pigs fitted with two sets of re-entrant cannulas in the proximal jejunum we failed to demonstrate an effect of varying amounts of soluble DF from mill fractions of oat on the amount of glucose absorbed from digesta in an isolated loop of jejunum (Johansen \& Bach Knudsen, 1994). Conversely, we found that diets with a higher level of starch resulted in a higher recovery of starch relative to the amount perfused.

In the present study we reduced the amount of starch in two of the diets used in the previous experiment (oat flour and oat bran) by adding purified wood cellulose. Purified cellulose is considered to have no effect on glucose absorption (Chang \& Li, 1984; Low et al. 1986). The purpose was to study whether a reduction in the starch load to the proximal intestine would elicit any effect of the soluble DF on glucose absorption from the isolated loop and simultaneously study the effect of soluble DF from oats and cellulose on the duodenal output.

\section{EX PER I MENT AL}

\section{Animals and surgery}

Four crossbred castrated male pigs of $35 \cdot 1$ (SD 2.3) $\mathrm{kg}$ initial live weight were used in the present experiment. Before surgery the pigs were sedated with $4 \mathrm{mg}$ Sedaperone Vet. (Janssenpharma A/S, Birkerød, Denmark)/kg live weight given intramuscularly and anaesthetized with $5 \mathrm{mg}$ Hypnodil Vet. (Janssenpharma A/S) $/ \mathrm{kg}$ given intravenously. The pigs were then intubated and anaesthesia maintained with halothane (2-bromo-2-chloro1.1.1-trifluorethane) in $\mathrm{O}_{2}(10 \mathrm{ml} / 1 ; 2000 \mathrm{ml} / \mathrm{min})$ using a closed circuit (bag-in-bottle) ventilator (Dameca MCM801; Dameca, Rødovre, Denmark). After a laparotomy was performed on the right flank the halothane concentration was reduced to $5 \mathrm{ml} / 1 \mathrm{O}_{2}$ during surgery. Two sets of re-entrant cannulas were placed in the jejunum according to the procedure described by Rainbird et al. (1984) and in detail by Horszczaruk et al. (1974). The first set of re-entrant cannulas was placed 2.5 (SD 0.9) $\mathrm{m}$ from the pylorus and the second set 2.1 (SD 0.4) $\mathrm{m}$ distal to the first. After 10-14 d of recovery, experiments were carried out for four consecutive weeks.

The distance between the stomach and the first cannula and the length of the intestinal loop were measured after completion of the experiment.

\section{Diets and feeding}

The chemical composition of the experimental diets is given in Table 1. The oat flour (diet F) was prepared at Carlsberg Research Laboratory, Copenhagen as described in detail by Bach Knudsen et al. (1993), and oat bran (diet B) was commercially available fractions of oats obtained from Kungsörnen AB, Järna, Sweden. To these oat fractions were added $148 \mathrm{~g} / \mathrm{kg}$ diet of technically pure wood cellulose obtained from A. G. Frisenette \& Sønner, Egsmark, Denmark (diets FC and BC). The total daily intake was $45 \mathrm{~g} / \mathrm{kg}$ body weight of diets $F$ and $B$ and $40 \mathrm{~g} / \mathrm{kg}$ body weight of diets FC and BC. The water intake was 2.5 times the amount of feed. All diets were supplemented with a vitamin-mineral mixture and casein to give approximately the same daily protein intake. $\mathrm{Cr}_{2} \mathrm{O}_{3}(10 \mathrm{~g} / \mathrm{kg})$ was added as solidphase marker. The pigs were fed on the diets for 1 week each in a $4 \times 4$ Latin square design in three equal meals at $07.00,15.00$ and 22.00 hours. The diets were changed over a $3 \mathrm{~d}$ 
Table 1. Composition of experimental diets

\begin{tabular}{|c|c|c|c|c|}
\hline Diet... & $\mathbf{F}$ & FC & B & BC \\
\hline \multicolumn{5}{|l|}{ Ingredients $(\mathrm{g} / \mathrm{kg})$} \\
\hline Oat flour & 858 & 637 & - & - \\
\hline Oat bran & - & - & 933 & 683 \\
\hline Cellulose & - & 148 & - & 148 \\
\hline Casein & 102 & 146 & 27 & 92 \\
\hline Soyabean oil & - & 26 & - & 34 \\
\hline Vitamin-mineral mixture* & 30 & 33 & 30 & 33 \\
\hline $\mathrm{Cr}_{2} \mathrm{O}_{3}$ & 10 & 10 & 10 & 10 \\
\hline \multicolumn{5}{|l|}{ Chemical composition (g/kg DM) } \\
\hline Starch & 565 & 425 & 393 & 259 \\
\hline Protein $(\mathrm{N} \times 6.25)$ & 209 & 224 & 235 & 245 \\
\hline HCl-fat & 79 & 89 & 94 & 105 \\
\hline Ash & 52 & 56 & 70 & 64 \\
\hline NSP & 54 & 198 & 163 & 292 \\
\hline S-NSP & 27 & 13 & 83 & 63 \\
\hline I-NSP & 26 & 184 & 80 & 229 \\
\hline Cellulose & 0 & 113 & 2 & 124 \\
\hline$\beta$-Glucan & 21 & 16 & 69 & 59 \\
\hline AX & 18 & 48 & 50 & 75 \\
\hline Xylose & 8 & 37 & 26 & 53 \\
\hline Arabinose & 7 & 6 & 18 & 15 \\
\hline Uronic acid & 4 & 5 & 5 & 8 \\
\hline Klason lignin & 8 & 7 & 23 & 18 \\
\hline Dietary fibre & 62 & 204 & 186 & 310 \\
\hline Gross energy (MJ/kg DM) & $19 \cdot 58$ & 19.84 & $19 \cdot 61$ & 19.97 \\
\hline $\mathrm{Cr}_{2} \mathrm{O}_{3}$ & $10 \cdot 0$ & $10 \cdot 6$ & $10 \cdot 9$ & $10 \cdot 9$ \\
\hline
\end{tabular}

F, oat flour; FC, oat flour + cellulose; B, oat bran; BC, oat bran + cellulose; HCl-fat, hydrochloric acidhydrolysed fat; NSP, non-starch polysaccharides; S-NSP, soluble non-starch polysaccharides; I-NSP, insoluble non-starch polysaccharides; AX, arabinoxylan; dietary fibre, NSP + Klason lignin; DM, dry matter.

* Provided (mg/kg diet): $\mathrm{Ca}_{2}\left(\mathrm{PO}_{4}\right)_{3}$ 17000, $\mathrm{K}_{2} \mathrm{PO}_{4} 5700, \mathrm{NaCl} 4000, \mathrm{CaCO}_{3} 2500, \mathrm{FeSO}_{4} .7 \mathrm{H}_{2} \mathrm{O} 212, \mathrm{ZnO} 85$, $\mathrm{MnO} 31, \mathrm{CuSO}_{4}, 5 \mathrm{H}_{2} \mathrm{O} 68, \mathrm{KI} 0 \cdot 2, \mathrm{Na}_{2} \mathrm{SeO}_{3}, 5 \mathrm{H}_{2} \mathrm{O} 0.6$, retinyl acetate 1.3, cholecalciferol 0.02, $\alpha$-tocopherol 43, menadione $1 \cdot 7$, ribofiavin $3 \cdot 4$, pantothenic acid $8 \cdot 5$, cobalamin $0 \cdot 02$.

period. Polyethylene glycol (molecular weight $4000 ;$ PEG) was added as a water-soluble marker (10 g per meal) in the periods where digesta were collected. General handling of pigs during the experiment is described by Johansen \& Bach Knudsen (1994).

\section{Collection and perfusion methods}

Twice weekly the cannulas were disconnected immediately before the morning feed to allow collection of digesta from the first cannula and perfusion through the isolated loop over an $8 \mathrm{~h}$ study period, essentially as described by Johansen \& Bach Knudsen (1994). The first collection was performed after $2 \mathrm{~d}$ on the new diet and the second collection $2 \mathrm{~d}$ later. Digesta were continuously collected from the first cannula and perfused through the isolated loop for $8 \mathrm{~h}$. At short intervals adapted to the flow-rate and at least at $0.5,1,2,3$, 5 and $7.5 \mathrm{~h}$ after feeding, digesta from the first cannula were weighed and a sample $(100 \mathrm{~g} / \mathrm{kg})$ taken for analysis. Samples were taken approximately three times within the first $0.5 \mathrm{~h}$. Digesta were re-heated to body temperature $\left(38^{\circ}\right)$ through silicone tubing and infused via a peristaltic pump into the isolated loop, which initially was rinsed with $500 \mathrm{ml}$ saline solution $(9 \cdot 1 \mathrm{~g} \mathrm{NaCl} / 1)$. Flow-rate during perfusion was adjusted according to the flow 
from the first cannula. Collection from the first cannula was stopped $7.5 \mathrm{~h}$ postprandially, whereas collection from the loop was extended by $30 \mathrm{~min}$, allowing digesta collected from the first cannula in the last period to be infused, followed by rinsing with $500 \mathrm{ml}$ saline solution within $8 \mathrm{~h}$. Digesta were pooled into three periods: $0-1,1-3$, and 3-7.5 h for the first cannula and $0-1,1-3,3-8 \mathrm{~h}$ after feeding for the second cannula respectively. Samples were frozen immediately after collection.

Since the loop was not rinsed between the three periods, material infused in one period could be collected in the following period, thus preventing calculation of the recovery in each individual period.

\section{Analytical methods}

All chemical analyses on diets and digesta were performed in duplicate. Analyses of $\mathrm{Cr}_{2} \mathrm{O}_{3}$ (Schurch et al. 1950) and PEG (Hyden, 1956) were performed on wet materials. All other analyses were carried out on freeze-dried materials. Dry matter (DM) was determined by freeze-drying followed by drying at $105^{\circ}$ for $24 \mathrm{~h}$. Protein $(\mathrm{N} \times 6 \cdot 25)$ was determined by the Kjeldahl method using a Kjel-Foss 16210 automatic analyser (Foss Electric A/S, Hillerød, Denmark) and gross energy was measured in a LECO AC 300 automated calorimeter system 789-500 (LECO, St Joseph, MI, USA). Ash was analysed according to the American Association of Official Analytical Chemists (1975) and fat was extracted with diethyl ether after acid-hydrolysis (Stoldt, 1952). Starch was analysed enzymically as described by Bach Knudsen et al. (1993). NSP and lignin were analysed as described in detail by Bach Knudsen et al. (1993). $\beta$-Glucan was determined by the enzymic method of McCleary \& Glennie-Holmes (1985; MegaZyme Pty Ltd, North Rocks, NSW, Australia).

Viscosity of the supernatant fraction of digesta was measured immediately after centrifugation at $12000 \mathrm{~g}$ for $20 \mathrm{~min}$ at $4^{\circ}$ in a Brookfield LVTDV-II cone/plate viscometer (Brookfield Engineering Laboratories Inc., Stoughton, MA., USA) at $38^{\circ}$ and shear rates from 2.25 to $450 \mathrm{~s}^{-1}$. Absolute viscosity (mPa.s) is presented at $45 \mathrm{~s}^{-1}$.

\section{Calculation and statistical analyses}

The content of polysaccharide residues was calculated as anhydrosugars. Arabinoxylan (AX) was calculated as the sum ofarabinose, xylose and uronic acid.

All recovery and net disappearance measurements from the loop were calculated either quantitatively or relative to $\mathrm{PEG}$ and $\mathrm{Cr}_{2} \mathrm{O}_{3}$ or $\mathrm{AX}$ as markers. All results were standardized to a feed intake of $500 \mathrm{~g}$ dry feed and $1250 \mathrm{ml}$ water. Net disappearance over the isolated loop is given per $m$ jejunum.

Cumulative recovery of digesta, DM, $\mathrm{Cr}_{2} \mathrm{O}_{3}, \mathrm{PEG}$, starch, NSP and AX from the first cannula was calculated as:

$$
R t_{i}=\sum M_{t_{0-i}} / \text { intake, }
$$

where $\sum M_{t_{0-i}}$ is the amount of a certain component collected from the first cannula from feeding $\left(t_{0}\right)$ to time $t_{i}$.

Mouth to jejunum transit was expressed as mean transit time (MTT)

$$
\text { MTT }=\frac{\sum_{i=0}^{n} M_{t_{i}} \times t_{i}}{\sum_{i=0}^{n} M_{t_{i}}},
$$

where $M_{t_{i}}$ is the amount collected in the $i$ th period of collection at time $t_{i}$ postprandially. $t_{0}$ is time of feeding and $t_{i}$ is the midpoint of the collection period. 
Apparent disappearance (AD) per $m$ intestine from the isolated loop was calculated as the difference in amount collected before and after perfusion of the loop and corrected for sampling and length of the loop.

$$
\mathrm{AD}=\frac{\sum M_{a}-\sum M_{b}}{L},
$$

where $\sum M_{a}$ is the total amount of a certain component collected from first cannula corrected for sampling and $\sum M_{b}$ the total amount collected from the second cannula after rinsing the loop and $L$ is the length of loop.

Recovery (R) of nutrients and markers per m loop was calculated as

$$
\mathbf{R}=1-\frac{\mathrm{AD}}{\sum M_{a}} .
$$

Relative recovery (RR) and apparent absorption (AA) of components could then be calculated assuming full recovery of the external markers from the loop. This corrects for losses during handling that are not caused by absorption:

$$
\mathbf{R}=\frac{\mathbf{R}_{\mathrm{dc}}}{\mathbf{R}_{\text {markers }}},
$$

where $R_{d c}$ is the recovery of a dietary component and $R_{\text {markers }}$ is the averaged recovery of the liquid- and solid-phase markers.

$$
\mathrm{AA}=(1-\mathrm{RR}) \times \sum M_{a} .
$$

Values from the first and second day of collection for each diet were averaged before statistical analysis as no significant difference between days was identified.

Analysis of variance was performed as

$$
X_{i j k}=\mu+\alpha_{i}+\beta_{j}+\alpha \beta_{i j}+\delta_{k}+\gamma_{l}+\epsilon_{i j k l},
$$

where $\mu$ is the overall mean, $\alpha_{i}$ is the effect of oat source, $\beta_{j}$ is the effect of cellulose, $\alpha \beta_{i j}$ is the interaction between oat source and cellulose, $\delta_{k}$ is the effect of week, $\gamma_{t}$ is the effect of animal and $\epsilon_{i j k l}$ is an independent normally distributed $\left(0, \sigma^{2}\right)$ random variable.

Before statistical analysis, data for viscosity were subjected to $\log$ transformation (Snedecor \& Cochran, 1973). Results are given as antilog of logarithmic means with their standard errors.

All statistical calculations were performed using a general-purpose statistical package (StatView) and a general linear-modelling package (SuperAnova; Abacus concepts, Berkeley, CA., USA).

\section{RESULTS}

Viscosity of jejunal contents

In the jejunal contents collected within the first hour only the viscosity of digesta from pigs fed on diet B was significantly elevated (34.9 (SE 1.9) mPa.s) when compared with the other diets (2.8 (SE 1.3) $\mathrm{mPa} . \mathrm{s})$. There was an interaction between oat source and cellulose supplementation $(P=0.012)$ and both the use of oat flour instead of oat bran and the addition of cellulose reduced the viscosity of digesta collected the first hour after feeding. The viscosity of digesta collected $1-3 \mathrm{~h}$ postprandially was not significantly different. Mean 
values were 4.0 (SE 1.2), 2.7 (SE 1.2), 15.7 (SE 2.8) and 10.5 (SE 1.7) mPa.s when feeding diets $\mathrm{F}, \mathrm{FC}, \mathrm{B}$ and $\mathrm{BC}$ respectively.

Flow from the proximal jejunal cannula

All results are based on an intake of $1750 \mathrm{~g}$ feed mixture consisting of $500 \mathrm{~g}$ dry feed and $1250 \mathrm{~g}$ water. In general, the output from the first jejunal cannula was characterized by a rapid flow of dietary components and markers in the first hour after feeding (Fig. 1). This was followed by a three- to fivefold reduction in the flow-rate $1-3 \mathrm{~h}$ postprandially and then by another $50 \%$ reduction in flow-rate $3-7.5 \mathrm{~h}$ postprandially.

Digesta. Cellulose supplementation significantly reduced the output of digesta in the first half hour after feeding $(P=0.017)$ with a mean recovery of the cellulose-supplemented diets of 0.46 (SE 0.05) compared with 0.62 (SE 0.04) for their unsupplemented counterparts. The substitution of oat flour (0.58 SE 0.06) for oat bran ( $0.50 \mathrm{SE} \mathrm{0.05)}$ had no effect on digesta output. At 2-3 h after feeding there was an interactive effect of oat source and cellulose addition $(P<0.021)$. By the end of the collection period the output of digesta was higher in the diets with cellulose being significant at $3 \mathrm{~h}(P=0.031)$ and $5 \mathrm{~h}(P=0.024)$ after feeding but not at $7.5 \mathrm{~h}(P=0.059)$ after feeding.

Dry matter and carbohydrates. Substitution of oat flour with oat bran in the diet significantly reduced the output of DM $(P=0.003)$, starch $(P=0.003)$, NSP $(P=0.004)$ and AX $(P=0.009) 1 \mathrm{~h}$ after feeding. Addition of cellulose significantly reduced the amount collected within $1 \mathrm{~h}$ for DM $(P=0.032)$ and starch $(P=0.049)$ but not for NSP $(P=0.061)$ and AX $(P=0.269)$.

This led to a recovery of DM of 0.70 (SE 0.04) when diet F was fed compared with 0.40 (SE 0.03) with diet BC (Fig. 1). The bran-based diets (B and BC) resulted in a fractional output of starch of 0.48 (SE 0.03 ) and 0.38 (SE 0.02) respectively in the first hour after feeding, whereas diet $F$ resulted in a fractional output of 0.69 (SE 0.03) and that for diet FC was 0.58 (SE 0.06). For NSP, 0.72 (SE 0.03) and 0.66 (SE 0.08) of the amount ingested was collected within the first hour for diets $\mathrm{F}$ and $\mathrm{FC}$ respectively, whereas the bran-based diets led to recoveries of 0.55 (SE 0.03) and 0.40 (SE 0.03) for diets B and BC respectively. At $3 \mathrm{~h}$ postprandially the oat source tended to reduce the output of NSP $(P=0.025)$ and AX $(P=0.038)$ with an interaction between oat source and cellulose supplementation at a significance level of $P=0.050$ and $P=0.006$ for NSP and AX respectively. The effect of oat source was not significant for DM $(P=0.062)$ and starch $(P=0.097)$, neither was the interaction between oat source and cellulose, with significance levels of $P=0.086$ for DM and $P=0.667$ for starch. The total amount of NSP recovered from the proximal jejunal cannula (relative to intake) was significantly lower from the bran-based diets (0.92 (SE 0.03)) when compared with the flour-based diets (1.03 (SE 0.04)). On the other hand, a recovery of starch of 0.85 (SE 0.03) from the flour-based diets was not significantly different from that of 0.74 (sE 0.02) obtained from the bran-based diets.

Markers. The recovery of PEG the first hour after feeding was affected significantly only by the addition of cellulose $(P=0.040)$ and not by the oat source used $(P=0 \cdot 124)$. The mean recovery from the cellulose-supplemented diets was 0.38 (SE 0.04) v. 0.53 (SE 0.05) for the unsupplemented diets. Later, no significant differences between dietary treatments were seen. The output of $\mathrm{Cr}_{2} \mathrm{O}_{3}$ in the first hour after feeding was reduced both by the ingestion of oat bran (0.48 (SE 0.04)) instead of oat flour (0.66 (SE 0.05)) and by the addition of cellulose, with a recovery of $\mathrm{Cr}_{2} \mathrm{O}_{3}$ in diets without cellulose supplementation of 0.63 (SE 0.04 ) and 0.51 (SE 0.06) when cellulose was added. The total output of $\mathrm{Cr}_{2} \mathrm{O}_{3}$ in the $7.5 \mathrm{~h}$ collection period was significantly affected by the oat source used $(P=0.029)$, with the bran-based diets giving lower recoveries $(0.93$ (SE 0.03)) than the flour-based diets (1.10 (SE 0.07)). However, all diets resulted in recoveries that were not significantly different from 1. 

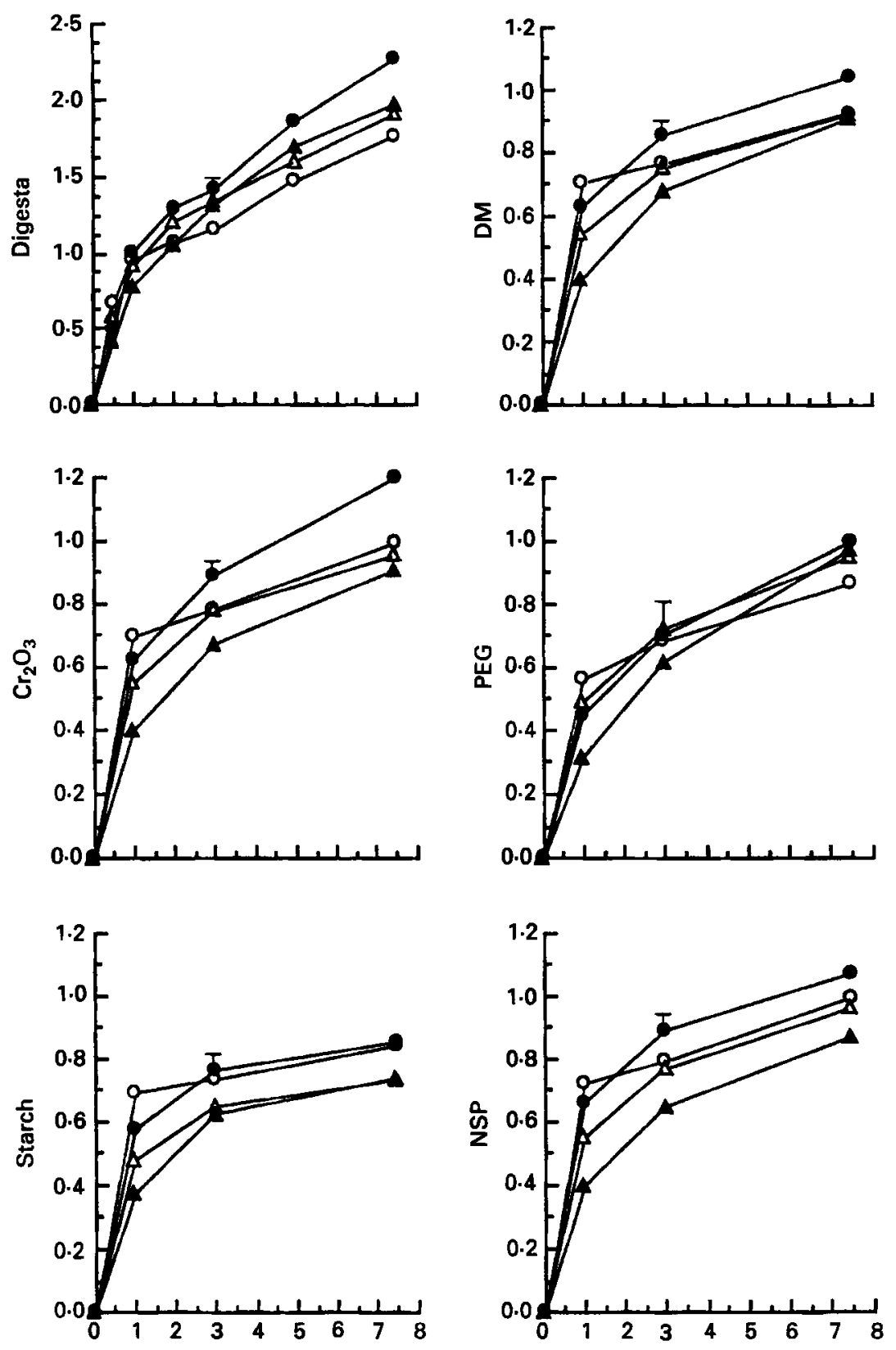

Time period after feeding (h)

Fig. 1. Cumulative output of digesta (relative to ingested feed and water), dry matter (DM), liquid-phase (polyethylene glycol; PEG) and solid-phase $\left(\mathrm{Cr}_{2} \mathrm{O}_{3}\right)$ markers, starch and non-starch polysaccharides (NSP) relative to ingested matter $0-7.5 \mathrm{~h}$ postprandially after feeding oat-flour and oat-bran diets with or without cellulose: $(O)$, oat flour; $(\Theta)$, oat flour + cellulose; $(\Delta)$, oat bran; $(\Delta)$, oat bran + cellulose. Points are mean values for four pigs with their standard error of means represented by vertical bars. For details of diets and experimental procedures, see pp. 718-721 and Table 1. 
Table 2. Mean transit time (MTT; $\min )$ of digesta, dry matter $(D M)$, dietary components (starch, non-starch polysaccharides (NSP) and arabinoxylan $(A X)$, and liquid-phase (polyethylene glycol; $\mathrm{PEG}$ ) and solid-phase $\left(\mathrm{Cr}_{2} \mathrm{O}_{3}\right)$ markers after feeding oat-flour and oatbran diets with or without cellulose $\dagger$

(Values are means for four pigs)

\begin{tabular}{|c|c|c|c|c|c|c|c|c|}
\hline \multirow[b]{2}{*}{ Diet... } & \multirow[b]{2}{*}{$F$} & \multirow[b]{2}{*}{ FC } & \multirow[b]{2}{*}{ B } & \multirow[b]{2}{*}{$\mathrm{BC}$} & \multirow[b]{2}{*}{ SE } & \multicolumn{3}{|c|}{$\begin{array}{c}\text { Statistical significance } \\
\text { of effect of }\end{array}$} \\
\hline & & & & & & Oat source & Cellulose & $\mathrm{O} \times \mathrm{C}$ \\
\hline Digesta & 134 & 153 & 132 & 149 & $14 \cdot 4$ & 0.668 & 0.053 & 0.921 \\
\hline Dry matter & 85 & 101 & 100 & 129 & $13 \cdot 2$ & $0.018^{*}$ & $0.016^{*}$ & 0.326 \\
\hline Starch & 70 & 81 & 82 & 105 & $13 \cdot 3$ & $0.036^{*}$ & $0.046^{*}$ & 0.421 \\
\hline NSP & 92 & 98 & 105 & 127 & $12 \cdot 3$ & $0 \cdot 012^{*}$ & 0.116 & 0.311 \\
\hline AX & 89 & 95 & 96 & 123 & $10 \cdot 8$ & $0.013^{*}$ & $0.038^{*}$ & 0.119 \\
\hline PEG & 101 & 137 & 123 & 163 & $30 \cdot 5$ & 0.162 & $0.048^{*}$ & 0.884 \\
\hline $\mathrm{Cr}_{2} \mathrm{O}_{3}$ & 95 & 124 & 104 & 130 & 20.9 & 0.484 & $0.040^{*}$ & 0.904 \\
\hline
\end{tabular}

F, oat flour; FC, oat flour + cellulose; B, oat bran; BC, oat bran + cellulose; $\mathbf{O} \times \mathbf{C}$, interaction between oat source and cellulose.

* $P<0.05$.

$\dagger$ For details of diets and experimental procedures, see pp. 718-721 and Table 1.

PEG was given as a pulse dose to the diet only when digesta were collected, with almost complete recovery from the proximal cannula within $7.5 \mathrm{~h}(0.95$ (SE 0.04$)$ ) and no significant differences between the diets. Since both markers were recovered fully within the $7.5 \mathrm{~h}$ collection period the stomach was considered as completely emptied within this period.

\section{Mean transit time}

Both replacement of oat flour by oat bran and supplementation with cellulose significantly increased MTT of DM, starch and AX, whereas cellulose supplementation had no significant effect on the MTT of NSP (Table 2). There were no significant differences between dietary treatments in the MTT of digesta, and MTT of the markers were only significantly reduced by the addition of cellulose to the diets.

\section{Perfusion of the isolated loop of jejunum}

Markers. $\mathrm{Cr}_{2} \mathrm{O}_{3}$ was fully recovered from all diets after perfusion of the loop (Table 3). The mean recovery of PEG was slightly lower (0.97 (SE 0.05)), but not significantly different from complete recovery. This indicates a minimal loss of material during perfusion.

Total NSP and $A X$. The NSP were quantitatively collected from all diets (1.03 (SE 0.09) and 1.03 (SE 0.05 ) for NSP and AX respectively). The main effect of relating the recovery to the markers was a reduction in the standard error.

$D M$. The recovery of DM relative to the markers was 0.96 (SE 0.05 ), with no significant differences between diets. Consequently, the calculated apparent absorption of DM corrected for markers was 19 (SE 17) g/m intestine, with no significant differences between diets.

Starch. The addition of cellulose significantly reduced the recovery of starch, when this was related to the recovery of external markers. However, when the recovery of starch was related to the recovery of $\mathrm{AX}$ (with the assumption of complete recovery of $\mathrm{AX}$ ) both the oat source and cellulose supplementation had strongly significant effects. The net 
Table 3. Recovery of liquid-phase (polyethylene glycol; $\mathrm{PEG}$ ) and solid-phase $\left(\mathrm{Cr}_{2} \mathrm{O}_{3}\right)$ markers, dry matter (DM) and dietary components (starch, non-starch polysaccharides $(N S P)$ and arabinoxylan $(A X))$ and absorption $(\mathrm{g} / \mathrm{m}$ intestine) of $D M$ and starch in an isolated loop of jejunum after perfusion of digesta from pigs fed on oat-flour and oat-bran diets with or without cellulose $\dagger$

(Values are means for four pigs)

\begin{tabular}{|c|c|c|c|c|c|c|c|c|}
\hline \multirow[b]{2}{*}{ Diet... } & \multirow[b]{2}{*}{$\mathbf{F}$} & \multirow[b]{2}{*}{ FC } & \multirow[b]{2}{*}{ B } & \multirow[b]{2}{*}{$\mathbf{B C}$} & \multirow[b]{2}{*}{ SE } & \multicolumn{3}{|c|}{$\begin{array}{l}\text { Statistical significance } \\
\text { of effect of: }\end{array}$} \\
\hline & & & & & & $\begin{array}{l}\text { Oat } \\
\text { source }\end{array}$ & Cellulose & $\mathrm{O} \times \mathrm{C}$ \\
\hline \multicolumn{9}{|l|}{ Recovery } \\
\hline $\begin{array}{c}\text { Markers } \\
\mathrm{Cr}_{2} \mathrm{O}_{3} \\
\mathrm{PEG}^{2}\end{array}$ & $\begin{array}{l}1.00 \\
1.03 \\
0.97\end{array}$ & $\begin{array}{l}1.00 \\
1.02 \\
0.98\end{array}$ & $\begin{array}{l}0.98 \\
1.01 \\
0.96\end{array}$ & $\begin{array}{l}1.00 \\
1.02 \\
0.98\end{array}$ & $\begin{array}{l}0.032 \\
0.032 \\
0.045\end{array}$ & $\begin{array}{l}0.698 \\
0.652 \\
0.858\end{array}$ & $\begin{array}{l}0.589 \\
0.747 \\
0.518\end{array}$ & $\begin{array}{l}0.491 \\
0.565 \\
0.678\end{array}$ \\
\hline \multirow{2}{*}{$\begin{array}{l}\text { DM corrected for markers } \\
\text { Starch corrected for: Markers }\end{array}$} & 0.96 & 0.93 & 0.97 & 0.98 & 0.045 & 0.179 & 0.550 & 0.476 \\
\hline & 0.91 & 0.85 & 0.88 & 0.82 & 0.032 & 0.117 & $0.018^{*}$ & 0.893 \\
\hline AX & 0.88 & 0.84 & 0.82 & 0.80 & 0.011 & $0.0001^{* * *}$ & $0.001^{* *}$ & 0.067 \\
\hline NSP: Total & 1.03 & 1.00 & 1.06 & 1.01 & 0.089 & 0.703 & 0.454 & 0.869 \\
\hline Corrected for markers & 1.04 & 1.01 & 1.08 & 1.01 & 0.064 & 0.470 & 0.164 & 0.516 \\
\hline AX: Total & 1.03 & 1.02 & 1.05 & 1.03 & 0.063 & 0.760 & 0.661 & 0.919 \\
\hline Corrected for markers & 1.04 & 1.03 & 1.07 & 1.03 & $0-045$ & 0.509 & 0.344 & 0.574 \\
\hline \multicolumn{9}{|l|}{ Absorption ( $\mathrm{g} / \mathrm{m}$ intestine) } \\
\hline DM corrected for markers & $19 \cdot 8$ & 31.7 & 11.6 & $11 \cdot 2$ & $17 \cdot 17$ & 0.146 & 0.529 & 0.501 \\
\hline \multirow{2}{*}{$\begin{array}{l}\text { Starch corrected for: Markers } \\
\text { AX }\end{array}$} & 18.9 & 23.6 & 17.0 & 15.8 & $6 \cdot 26$ & $0 \cdot 172$ & 0.599 & 0.378 \\
\hline & $26 \cdot 0$ & $27 \cdot 2$ & 23.4 & 17.6 & 2.01 & $0.024^{*}$ & 0.295 & 0.127 \\
\hline
\end{tabular}

F, oat flour; FC, oat flour + cellulose; B, oat bran; BC, oat bran +cellulose; $\mathrm{O} \times \mathrm{C}$, interaction between oat source and cellulose.

$* P<0.05, * * P<0.01, * * * P<0.001$.

$\dagger$ For details of diets and experimental procedures, see pp. 718-721 and Table 1.

absorption of starch corrected for recovery of AX was significantly reduced in the branbased diets when compared with the flour-based diets, but this effect was not significant if starch absorption was related to the recovery of the external markers.

\section{DISCUSSION}

The output from the first jejunal cannula was characterized by a rapid flow the first hour after feeding followed by a drastic reduction in the flow-rate $1-3 \mathrm{~h}$ postprandially. Feeding diets with higher amounts of DF, either as cellulose or as oat DF, slowed the initial jejunal output of the DM components. This suggests that a higher level of DF, irrespective of origin, had a prolonging effect on gastric emptying. Diets FC and B had almost identical MTT that were slightly longer than that of diet $F$, whereas diet $B C$ resulted in an even more prolonged gastric emptying. However, diet B tended to result in a smaller output $1 \mathrm{~h} \mathrm{after}$ feeding than diet FC, in spite of a similar DF content. The reason for this could be the higher proportion of soluble DF in the former, which creates a more viscous digesta, thereby delaying gastric emptying. Recent results with re-entrant cannulated pigs fed on wheat-flour and oat-mill fractions with varying contents of soluble DF (Johansen \& Bach Knudsen, 1994) showed that the rate of gastric emptying was not directly related to the dietary content of soluble DF, but other factors like the food micro structure, particle size 
and composition of the other dietary components could be of equal importance. The present results suggest that cellulose delays gastric emptying of both the liquid and solid phases of digesta, although this component does not enhance viscosity. This is contradictory to previous reports on the effect of cellulose on gastric emptying (Rainbird \& Low, 1986; Low, 1990). Cellulose is an insoluble DF source and generally considered rather inert in the upper gastrointestinal tract. However, purification of cellulose changes the physical characteristics, as seen with many other DF sources (Cummings, 1984; Wood et al. 1990), and the cellulose used in the present experiment was found to have a high water-binding capacity ( $7.2 \mathrm{~g}$ water/g DM). MTT of DM and the fibre components (NSP and AX) were largely identical. The MTT of starch was shorter, which presumably suggests that a higher proportion of starch in the gut contents collected in the later time periods after feeding was absorbed before the proximal cannula. The lower flow-rate in the later stages after ingestion would allow more time for digestion and absorption.

The total output of digesta from the first re-entrant cannula over the $7.5 \mathrm{~h}$ collection period was $1 \cdot 8-2 \cdot 3$ times the amount of feed and water ingested corresponding to an endogenous secretion of gastric juice, bile and pancreatic juice of $1 \cdot 3-2 \cdot 2$ litres. The effect of diet on endogenous secretion was not directly associated with the content of DF, since cellulose tended to have a greater stimulatory effect on endogenous secretion than the DF from the oat bran. In a previous study an oat-bran diet with a $5 \%$ lower content of DF than diet $B$ resulted in a much larger output of digesta ( 3.2 litres) than the 1.6 litres obtained with diet B in the present study (Johansen \& Bach Knudsen, 1994). The content of DF, thus, only partly explains the stimulatory effect on endogenous secretion (Zebrowska et al. 1983; Johansen \& Bach Knudsen, 1994).

Delayed absorption of glucose from the small intestine, irrespective of any effect on gastric emptying, as suggested by many workers (e.g. Jenkins et al. 1978; Blackburn et al. 1984; Flourie et al. 1984), would result in a smaller net absorption of glucose from the isolated loop. This was not supported by the findings of the present study. In contrast, we found that the relative recovery of starch decreased with a higher content of DF in the diet. This was to some extent supported by the amount of starch collected from the proximal cannula where the bran-based diets tended to have a lower total recovery than the flourbased diets, although this was not statistically significant. The incomplete recovery from the proximal cannula must be due to absorption before the cannula since there was almost complete recovery of the markers and fibre components within the $7.5 \mathrm{~h}$ collection period. In a recent experiment with diets based on wheat flour and mill fractions of oats we obtained results similar to those of the present study, with no significant differences in the net absorption of starch and a consistent trend for a lower recovery of starch with a higher content of soluble DF, i.e. lower content of starch in the diet (Johansen \& Bach Knudsen, 1994). This is inconsistent with results obtained with isolated DF sources and glucose solutions (e.g. Johnson \& Gee, 1981 ; Rainbird et al. 1984). An interpretation of the results could be that the amount of substrate exceeds the capacity of the intestinal brush-border to remove the starch degradation products from the proximal jejunum. Furthermore, Rérat et al. (1984) suggested that the rate-limiting factor for glucose appearance in the portal blood from maize starch is the enzymic hydrolysis rate in the duodenum, not gastric emptying or pancreatic $\alpha$-amylase (EC 3 .2 . 1 . 1) secretion. Gray (1992) suggested instead that the rate-limiting step in starch assimilation is the final glucose transport into the enterocytes because intraluminal and surface digestion of starch and its oligosaccharide products are extremely efficient. Consequently, any effect of soluble DF on the rate of absorption must be exerted either with lower concentrations of absorbable carbohydrate or more distal in the small intestine. Blackburn \& Johnson (1983) have demonstrated that the effectiveness of guar gum to inhibit absorption of glucose disappears with increasing 
glucose concentrations, consistent with a smaller effect of soluble DF on postprandial glycaemia at a higher consumption of carbohydrate (Jenkins et al. 1981; Sels et al. 1992). Thus, although starch absorption when related to the recovery of $\mathrm{AX}$ indicates an effect of bran on absorption in the upper jejunum, impaired absorption may be more efficient more distal in the small intestine where the concentration of absorbable nutrients is lower and concentration of DF higher. At first glance the recovery of glucose and DM from the first re-entrant cannula and the isolated loop might seem very high when considering the duodenum to mid jejunum as the primary site for carbohydrate assimilation. However, given the length of the loop, the obtained recoveries are in the same range as those obtained in the upper jejunum of normal pigs (Keys \& DeBarthe, 1974; Bach Knudsen et al. 1993).

The rather low and variable viscosity of the jejunal content of pigs in the present study is consistent with results obtained with digesta from the proximal third of the small intestine of normal pigs fed on oat bran (Johansen, 1993). Large diurnal and dietary variations in flow and endogenous secretion may explain this. It has been established that in vivo viscosity does not correlate very well with in vitro viscosity and the concentration of soluble DF in the diet (Edwards et al. 1987; Johansen, 1993; Roberts et al. 1995). On the other hand, a strong correlation has been found between net glucose absorption and in vivo zero-shear viscosity of jejunal content from pigs fed on a semi-purified diet supplemented with guar-gum flour (Roberts et al. 1995). However, DF as a part of plant foods needs to be solubilized from the cell-wall matrix in order to increase viscosity (Johansen, 1993). Isolated $\beta$-glucan has been reported to modify the gut contents of rats similarly to ground rolled oats (Lund et al. 1989), but in the latter case the large differences in the rheological behaviour in the proximal and distal small intestine were not considered. The primary site for absorption of carbohydrates is the duodenum and proximal-mid jejunum (Keys \& DeBarthe, 1974; Gray, 1992; Bach Knudsen et al. 1993) and, thus, viscosity should be measured at these sites when it is related to glucose absorption (Cherbut et al. 1990). Presumably, viscosity in the proximal jejunum does not play a major role in glucose absorption when diets containing soluble DF in intact plant cell walls are ingested. Viscosity may indirectly play a role by delaying gastric emptying. Alternatively, fibre-rich plant sources with the fibre enclosed in a rigid cell-wall matrix may reduce the glycaemic response by entrapping the nutrients (Wong et al. 1985; Heaton, 1990; Johansen, 1993), but this tends to induce malabsorption rather than just a delay in the absorption from the small intestine.

\section{Conclusion}

The present study shows that feeding diets with a higher content of DF, either in the form of DF from mill fractions of oat or as technically pure wood cellulose, to pigs reduced the initial flow-rate from re-entrant cannulas placed in the upper jejunum indicating a prolonged gastric emptying. Feeding diets with higher amounts of DF did not significantly reduce the amount of starch absorbed from an isolated loop in the proximal jejunum, instead a higher recovery of starch after perfusion was found with the diets providing more starch to the jejunal mucosa. This finding suggests that the rate-limiting factor for glucose absorption in the duodenum and proximal jejunum is the capacity of the intestinal mucosa to remove the carbohydrate substrate from the lumen, which overrides any effect of DF on glucose absorption. Therefore, a slower absorption obtained when feeding higher levels of DF appears to be an effect of the gastric emptying of dietary components rather than a direct effect in the small intestine.

This work was supported by the Danish Agricultural and Veterinary Research Council and the Danish Research Academy. The authors are indebted to Dr Henry Jørgensen for 
carrying out surgery. They would like to thank the technical staff at NIAS for animal care and skilful technical analyses and Drs Bjørn O. Eggum and Brittmarie Sandström for their advice during the work.

\section{REFERENCES}

Association of Official Analytical Chemists (1975). Official Methods of Analysis, 11th ed. Washington DC: Association of Official Analytical Chemists.

Bach Knudsen, K. E., Jensen, B. B. \& Hansen, I. (1993). Digestion of polysaccharides and other major components in the small and large intestine of pigs fed on diets consisting of oat fractions rich in $\beta$-D-glucan. British Journal of Nutrition 70, 537-555.

Blackburn, N. A. \& Johnson, I. T. (1983). The influence of guar gum on the movements of inulin, glucose and fluid in rat intestine during perfusion in vivo. Pflügers Archiv 397, 144-148.

Blackburn, N. A., Redfern, J. S., Jarjis, H., Holgate, A. M., Hanning, I., Scarpello, J. H. B., Johnson, I. T. \& Read, N. W. (1984). The mechanism of action of guar gum in improving glucose tolerance in man. Clinical Nutrition 66, 329-336.

Chang, M. L. W. \& Li, B. W. (1984). Effect of gel-forming undigestible polysaccharides versus cellulose on intestinal sugar concentrations and serum glucose levels in rats. Nutrition Reports International 30, 789-796.

Cherbut, C., Albina, E., Champ, M., Doublier, J. L. \& Lecannu, G. (1990). Action of guar gums on the viscosity of digestive contents and on the gastrointestinal motor function in pigs. Digestion 46, $205-213$.

Cummings, J. H. (1984). Cellulose and the human gut. Gut 25, 805-810.

Ebihara, K., Masuhara, R. \& Kiriyama, S. (1981). Major determinants of plasma glucose-flattening activity of a water-soluble dietary fiber: effects of konjac mannan on gastric emptying and intraluminal glucose-diffusion. Nutrition Reports International 23, 1145-1156.

Edwards, C. A., Blackburn, N. A., Craigen, L. D., Davison, P., Tomlin, J., Sugden, K., Johnson, I. T. \& Read, N. W. (1987). Viscosity of food gums determined in vitro related to their hypoglycemic actions. American Journal of Clinical Nutrition 46, 72-77.

Flourie, B. (1992). The influence of dietary fiber on carbohydrate digestion and absorption. In Dietary Fibre: A Component of Food: Nutritional Function in Health and Disease. ILSI Human Nutrition Reviews, pp. 181-196 [T. F. Schweizer and C. A. Edwards, editors]. London: Springer-Verlag.

Flourie, B., Vidon, N., Florent, C. \& Bernier, J. J. (1984). Effect of pectin on jejunal absorption and unstirred layer thickness in normal man. Gut 25, 936-941.

Gray, G. M. (1992). Starch digestion and absorption in nonruminants. Journal of Nutrition 122, 172-177.

Heaton, K. W. (1990). Concepts of dietary fibre. In Dietary Fibre: Chemical and Biological Aspects. Royal Society of Chemistry Special Publication no. 83, pp. 3-9 [D. A. T. Southgate, K. Waldron, I. T. Johnson and G. R. Fenwick, editors]. Cambridge: Royal Society of Chemistry.

Holt, S., Heading, R. C., Carter, D. C., Prescott, L. F. \& Tothill, P. (1979). Effect of gel fibre on gastric emptying and absorption of glucose and paracetamol. Lancet $\mathrm{i}, 636-639$.

Horszczaruk, F., Buraczewska, L. \& Buraczewski, S. (1974). Amount and composition of intestinal juice collected from isolated intestinal loops of jejunum. Roczniki nauk Rolniczych 95, 69-77.

Hyden, S. (1955). A turbidimetric method for the determination of higher polyethylene glucols in biological material. Kungliga Lantbrukshögskolans Annaler 22, 139-145.

Jenkins, D. J. A., Wolever, T. M. S., Leeds, A. R., Gassull, M. A., Haisman, P., Dilawari, J., Goff, D. V., Metz, G. L. \& Alberti, K. G. M. (1978). Dietary fibres, fibre analogues, and glucose tolerance: importance of viscosity. British Medical Journal i, 1392-1394.

Jenkins, D. J. A., Wolever, T. M. S., Taylor, R. H., Barker, H., Fielden, H., Baldwin, J. M., Bowling, A. C., Newman, H. C., Jenkins, A. L. \& Goff, D. V. (1981). Glycemic index of foods: a physiological basis for carbohydrate exchange. American Journal of Clinical Nutrition 34, 362-366.

Johansen, H. N. (1993). Dietary fibre from oats: physico-chemical properties and physiological function in the stomach and small intestine of pigs. $\mathrm{PhD}$ Thesis, The Royal Veterinary and Agricultural University, Copenhagen.

Johansen, H. N. \& Bach Knudsen, K. E. (1994). Effects of wheat-flour and oat mill fractions on jejunal flow, starch degradation and absorption of glucose over an isolated loop of jejunum in pigs. British Journal of Nutrition 72 , 299-313.

Johnson, I. T. (1990). Fibre sources for the food industry. Proceedings of the Nutrition Society 49, 31-38.

Johnson, I. T. \& Gee, J. M. (1981). Effect of gel-forming gums on the intestinal unstirred layer and sugar transport in vitro. Gut 22, 398-403.

Keys, J. E. \& DeBarthe, J. V. (1974). Site and extent of carbohydrate, dry matter, energy and protein digestion and the rate of passage of grain diets in swine. Journal of Animal Science 39, 57-62.

Low, A. G. (1990). Nutritional regulation of gastric secretion, digestion and emptying. Nutrition Research Reviews 3, 229-252.

Low, A. G., Zebrowska, T., Heppell, L. M. J. \& Smith, H. A. (1986). Influence of wheat bran, cellulose, pectin and low or high viscosity guar gum on glucose and water absorption from pig jejunum. Proceedings of the Nutrition Society 45, 55A. 
Lund, E. K., Gee, J. M., Brown, J. C., Wood, P. J. \& Johnson, I. T. (1989). Effect of oat gum on the physical properties of the gastrointestinal contents and on the uptake of D-galactose and cholesterol by rat small intestine in vitro. British Journal of Nutrition 62, 91-101.

McCleary, B. V.\& Glennie-Holmes, M. (1985). Enzymatic quantification of $(1 \rightarrow 3),(1 \rightarrow 4)$-D-glucan in barley and malt. Journal of the Institute of Brewing 91, 285-295.

Meyer, J. H., Gu, Y. G., Jehn, D. \& Taylor, I. L. (1988). Intragastric vs intraintestinal viscous polymers and glucose tolerance after liquid meals of glucose. American Journal of Clinical Nutrition 48, 260-266.

Rainbird, A. L. \& Low, A. G. (1986). Effect of various types of dietary fibre on gastric emptying in growing pigs. British Journal of Nutrition 55, 111-121.

Rainbird, A. L., Low, A. G. \& Zebrowska, T. (1984). Effect of guar gum on glucose and water absorption from isolated loop of jejunum in conscious growing pigs. British Journal of Nutrition 52, 489-498.

Rérat, A. A., Vaissade, P. \& Vaugelade, P. (1984). Absorption kinetics of some carbohydrates in conscious pigs. 2. Quantitative aspects. British Journal of Nutrition 51, 517-529.

Roberts, F. G., Low, A. G., Morgan, L. M. \& Ellis, P. R. (1995). The effect of high viscosity guar gum on net glucose absorption and net apparent insulin and GIP production in the portal blood of the growing pig: a relationship to physico-chemical changes in jejunal digesta. British Journal of Nutrition (In the Press).

Schurch, A. F., Lloyd, L. E. \& Crampton, E. W. (1950). The use of chromic oxide as an index for determining the digestibility of a diet. Journal of Nutrition 50, 629-636.

Sels, J.P., Debruin, H., Camps, M. H. T. A., Postmes, T. J. L., Menheere, P., Wolfenbuttel, B. H. R. \& Kruseman, A. C. N. (1992). Absence of guar efficacy in complex spaghetti meals on post-prandial glucose and c-peptide levels in healthy control and non-insulin-dependent diabetes-mellitus subjects. Hormone and Metabolic Research 26, 52-58.

Snedecor, G. W. \& Cochran, W. G. (1973). Statistical Methods, 6th ed. Ames, Iowa: The Iowa State University Press.

Stoldt, W. (1952). Suggestions for the standardisation of the determination of fat in foodstuffs. Fette, Seifen, Anstrichmittel 54, 206-207.

Torsdottir, I., Alpsten, M., Holm, G., Sandberg, A. S. \& Tolli, J. (1991). A small dose of soluble alginate-fiber affects post-prandial glycemia and gastric emptying in humans with diabetes. Journal of Nutrition 121, 795-799.

Wong, S., Traianedes, K. \& O'Dea, K. (1985). Factors affecting the hydrolysis of starch in legumes. American Journal of Clinical Nutrition 42, 38-43.

Wood, P. J., Braaten, J. T., Scott, F. W., Fiedel, D. \& Poste, L. M. (1990). Comparisons of viscous properties of oat and guar gum and the effects of these and oat bran on glycemic index. Journal of Agriculture and Food Chemistry 38, 753-757.

Zebrowska, T., Low, A. G. \& Zebrowska, H. (1983). Studies on gastric digestion of protein and carbohydrate, gastric secretion and exocrine pancreatic secretion in the growing pig. British Journal of Nutrition 49, 401-410. 